\title{
Levocarnitine in the management of fatigue in levothyroxine treated hypothyroid patients
}

\author{
Farjana Akhter ${ }^{1}$, Zesmin Fauzia Dewan ${ }^{1}$, M A Hasnat $^{2}$, Selina Akhter ${ }^{3}$ \\ ${ }^{1}$ Department of Pharmacology, Bangabandhu Sheikh Mujib Medical University, Dhaka, Bangladesh; \\ ${ }^{2}$ Department of Endocrinology, Bangabandhu Sheikh Mujib Medical University, Dhaka, Bangladesh; \\ ${ }^{3}$ Department of Pharmacology, Shaheed Suhrawardy Medical College, Dhaka, Bangladesh
}

\begin{abstract}
Background and objectives: Hypothyroid patients often complain of fatigue even after effective treatment. Thyroid hormone plays an important role in carnitine-dependent long chain fatty acid transport for oxidation and ultimate formation of ATP. Deficiency of L-carnitine has been presumed to disrupt ATP formation leading to fatigue. Present study was designed to assess the role of L-carnitine as a supplement to manage the fatigue state of hypothyroid patients.

Methods: Hypothyroid patients receiving levothyroxine $\left(\mathrm{L}-\mathrm{T}_{4}\right)$ and suffering from fatigue symptoms were enrolled. Patients were randomly divided into Group $A$ (Control group, $n=35$ ) and Group B (Experimental group, $\mathrm{n}=36$ ). Patients of Group A were treated with $\mathrm{L}-\mathrm{T}_{4}$ only and Group B patients received L-carnitine $2 \mathrm{~g} /$ day in addition to $L-T_{4}$ therapy for 8 weeks. Fatigue was assessed by fatigue severity scale (FSS), physical fatigue (PF) and mental fatigue (MF) scores. Data regarding fatigue status, serum thyroid stimulating hormone (TSH) and free thyroxine $\left(\mathrm{FT}_{4}\right)$ were collected at the beginning and after 8 weeks of intervention.

Result: The mean age of Group A and Group B patients was $33.5 \pm 8.1$ and $35.4 \pm 7.5$ years respectively ( $p>0.05$ ); and the mean body weight was $61.5 \pm 9.6 \mathrm{~kg}$ and $62.5 \pm 8.2 \mathrm{~kg}$ respectively ( $p>0.05$ ). The mean baseline values of different fatigue scores and the serum TSH and $\mathrm{FT}_{4}$ levels of patients of two groups were identical and not significantly different ( $p>0.05)$. In Group-A patients, the mean MF score improved significantly $(5.2 \pm 1.5$ vs $4.6 \pm 1.4 ; p=0.01)$ from baseline score after 8 weeks while the FSS and PF scores did not improve significantly $(p>0.05)$. In Group-B patients, the mean FSS, PF and MF scores improved significantly $(p<0.01)$ from baseline score after 8 weeks of treatment with L-carnitine along with $\mathrm{L}_{\mathrm{LT}} \mathrm{T}_{4}$ treatment. FSS, PF and MF scores of Group-B patients reduced significantly $(p<0.01)$ compared to Group-A patients after 8 weeks of treatment. FSS, PF and MF scores improved in $88.9 \%, 77.8 \%$ and $47.2 \%$ cases respectively in Group-B compared to $20 \%, 14.3 \%$ and $5.7 \%$ cases in Group-A. Lcarnitine was well tolerated and no severe adverse event was recorded.
\end{abstract}

Conclusion: The results suggest that, administration of L-carnitine along with $L-T_{4}$ in hypothyroid patients significantly reduced physical and mental fatigue.

IMC J Med Sci 2019; 13(2): 008. EPub date: 15 January 2020

\section{Introduction}

Hypothyroidism is one of the common endocrine abnormalities in Bangladesh and all over the world. Thyroid dysfunction, especially hypothyroidism affects a significant number of people in Bangladesh [1-3]. Diffuse goiter has the highest incidence of $7.35 \%$, followed by subclinical $(6.59 \%$ to $15 \%)$ and clinical hypothyroidism (4.97\%) [4,5]. A recent study

\section{Address for Correspondence:}

Dr. Farjana Akhter, Assistant Professor, Department of Pharmacology, Green Life Medical College, 31 \& 31/1 Bir Uttam K.M. Shafiullah Sarak (Green Road), Dhaka, Bangladesh. Email: polynoble@gmail.com 
from Bangladesh has reported the prevalence of hypothyroidism as $7 \%$ in different occupational groups [6] and its rate is $48 \%$ among the entire thyroid disorders [7]. Therefore, a significant number of the population is suffering from hypothyroidism that requires thyroid hormone replacement therapy. However, many patients experience persistent fatigue and fatigue-related symptoms even after hormone replacement $[8,9]$.

Fatigue causes reduced ability to conduct daily activities, feeling of tiredness due to physical and/or mental exhaustion which in severe cases may lead to chronic fatigue syndrome (CFS) and is not improved in spite of rest [10]. CFS affected people is unable to lead a healthy personal, familial and social life which ultimately leads to psychological stress [11]. It is said that significantly decreased biosynthesis of carnitine occurs due to deficiency of thyroid hormone in hypothyroidism contributes in fatigue [12-14].

L-carnitine synthesized in the human body from lysine and methionine appears to be an essential carrier for fatty acids to enter the cell [15-18]. Lcarnitine transports long chain fatty acids into the mitochondria where ATP is synthesized. Thyroid hormone is involved in fatty acid oxidation and transfer of free fatty acids into the mitochondria $[19,20]$. Free fatty acids are converted into acyl-coA derivatives inside cells and needed to be transported into the inner mitochondrial membrane for the oxidation process. So, carriers are needed for this transport through the impermeable outer mitochondrial membrane. Lack of L-carnitine interrupts transport of long chain fatty acids into the mitochondria and less formation of ATP leads to deprivation of energy resulting in fatigue. This condition may be alleviated by exogenous administration of Lcarnitine. Reports suggest that $53 \%$ of patients with chronic illness such as hypothyroidism, diabetes mellitus or malignancy suffer from L-carnitine deficiency which might predispose to chronic fatigue state [21,22].

It is apparent that fatigue related symptoms in hypothyroid patients are related to L-carnitine deficiency. When hypothyroid patient is treated with $\mathrm{L}-\mathrm{T}_{4}$, it promotes carnitine synthesis and also accelerates mitochondrial fatty acid oxidation by utilizing carnitine. This may lead to relative carnitine deficiency which may be responsible for development of fatigue. L-carnitine administration has been found to produce potentially favorable effects on fatigue related symptoms in hypothyroid patients receiving thyroid hormone replacement [23].

The present study has therefore been designed to investigate the effect of L-carnitine supplementation on fatigue related symptoms in hypothyroid patients.

\section{Materials and methods}

This randomized controlled trial was carried out in the Department of Pharmacology and Department of Endocrinology of Bangabandhu Sheikh Mujib Medical University (BSMMU), Dhaka, from September 2016 to February, 2018. The study was approved by the Institutional Review Board (IRB). This study was also registered in ClinicalTrials.gov and the ID number was (NCT03372772). Written informed consent was obtained from all participants prior to enrollment in the study.

Study population: Participants were enrolled by following specific inclusion criteria: clinically diagnosed as primary hypothyroid patients having symptoms of fatigue with fatigue severity scale score $\geq 30$, age $20-50$ years of both sexes, receiving levothyroxine for last 6 months, and serum $\mathrm{FT}_{4}$ and TSH levels within normal reference range $\left(\mathrm{FT}_{4}\right.$ : 10.8 $1.8 \mathrm{ng} / \mathrm{dl}$ and TSH: 0.35-5.5 $\mu \mathrm{lU} / \mathrm{mL}$ ). Patients with acute or chronic liver diseases, anaemia, diabetes mellitus, cardiovascular disease (such as heart failure, arrhythmia and uncontrolled hypertension), psychological disorders (such as depression, anxiety disorder, schizophrenia, alcoholism), fatigue disorder due to other systemic diseases, serious infections or terminal illness (such as tuberculosis, HIV or malignant tumor), autoimmune diseases (such as rheumatoid arthritis, SLE or multiple sclerosis), impaired renal function were excluded from the study. Pregnant women, nursing mothers and patients taking drugs such as corticosteroid, iron, calcium, amantadine, lithium, carbamazepine, phenobarbital, beta-blockers were also excluded. After enrollment, baseline information regarding age, sex, body weight, blood pressure and pulse rate were obtained and recorded in a data sheet. 
Blood collection and estimation of TSH and free $T_{4}$ $\left(\boldsymbol{F T} \mathbf{T}_{4}\right)$ : About $6 \mathrm{ml}$ of blood was collected aseptically from each patient following overnight fasting for the measurement of serum TSH and $\mathrm{FT}_{4}$ at the initiation of study and again after 8 weeks of intervention. Serum TSH and $\mathrm{FT}_{4}$ levels were estimated by automated analyzer (Unicel DXI-600) in Department of Microbiology and Immunology of BSMMU.

Measurement of fatigue: Fatigue of clinical importance was measured by the following fatigue scale:

Fatigue severity scale: The fatigue severity scale (FSS) is a 9-item self-report questionnaire scale developed in 1989 [24]. The FSS is a valid instrument and a specific questionnaire to assess and quantify fatigue for clinical and research purpose $[25,26]$. FSS score range is from 9 to 63 . A lowered total score indicates less fatigue in everyday life.
Wessely-Powell fatigue score: Wessely and Powell fatigue scale consists of two scales measuring physical fatigue (PF) and mental fatigue (MF). PF has eight items each having a score from 0 (no fatigue) to 2 (highest possible fatigue) with total score of 0 to 16 and MF has five item each having a score from 0 (no fatigue) to 2 (highest possible fatigue) with total score of 0-10 [27].

Modified Bengali version of FSS and Wessly-Powell fatigue score: For linguistic, cultural variation and easy understanding, 'Fatigue severity scale' and 'Wessly-Powell fatigue score' questionnaires were translated into Bengali.

Piloting of questionnaire: A pilot study was conducted in ten hypothyroid patients at the outpatient department of Endocrinology, BSMMU to identify problem with the wording, answering the questions or any difficulties in filling the form. They were asked to comment on any difficulties to

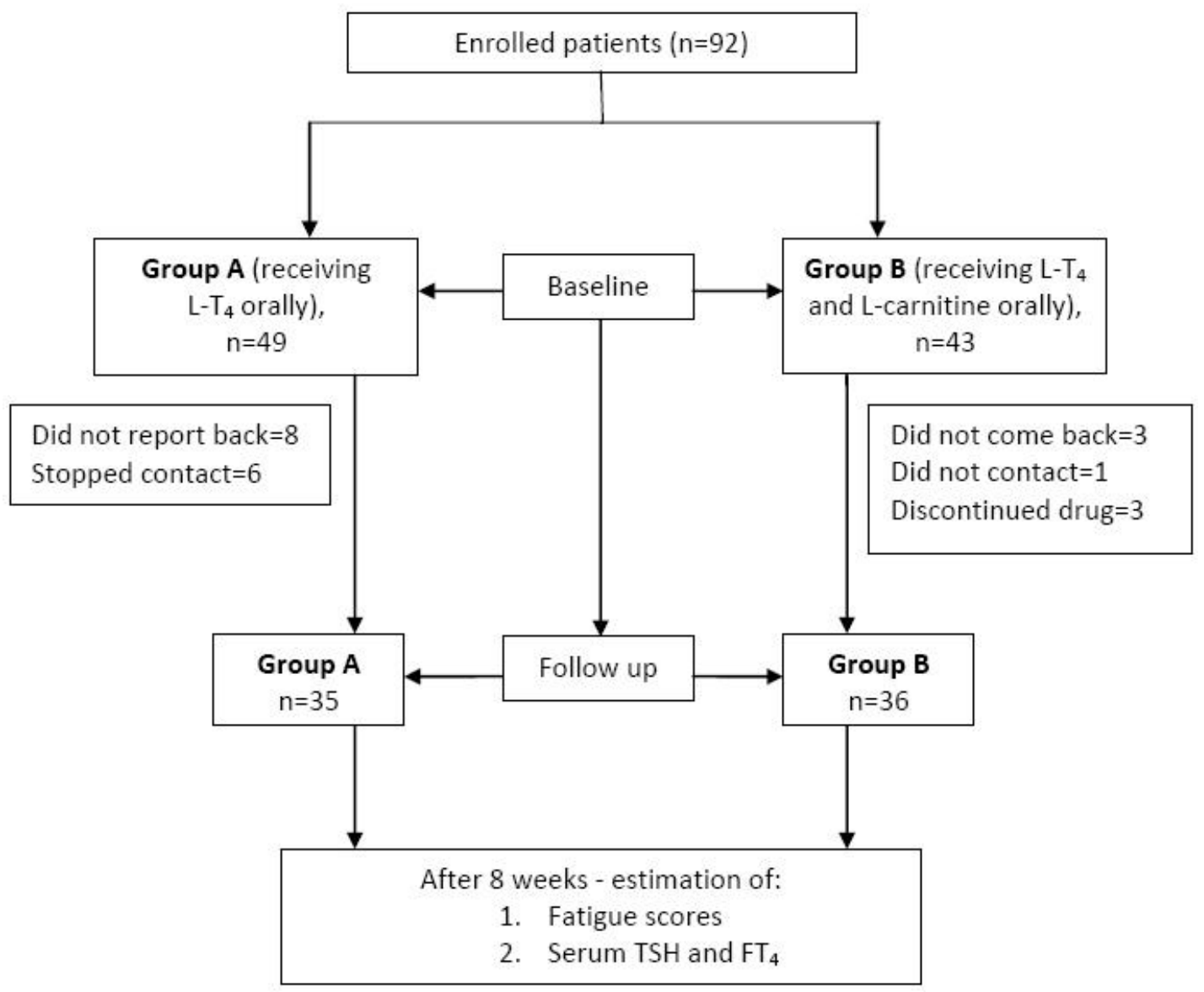

Figure-1: The procedure of the study 
understand the question. Only minor changes in questionnaire were done and no major modification was required.

Treatment schedule: All enrolled patients were randomized into Control group (Group- A) and Experimental group (Group-B). Group-A participants were allowed to continue with once daily appropriate oral dose of L-T 4 for 8 weeks. Group-B participants were treated with $2 \mathrm{gm}$ oral solution of L-carnitine daily in two divided doses in addition to $L-T_{4}$ therapy for 8 weeks. Patients were advised to take $\mathrm{L}^{-} \mathrm{T}_{4}$ in the morning before meal and L-carnitine in the morning and at night after meal. Compliance sheets were provided to each patient. Consumption of medicine was ensured by either telephone call, return of empty vials or from the patient's compliance sheet. After 8 weeks, fatigue level was estimated again and blood was collected from both groups to measure the same parameters measured at baseline. Patients were asked to report adverse effects (if observed) of the medication given in the study. The procedure of the study is summarized in Figure-1.

Analysis of data: All data were systematically recorded and Chi-square and student's t-tests were used as required.

\section{Results}

Initially after screening, 92 participants were enrolled and were randomized into Control group (Group A, n=49) and Experimental group (Group B, $n=43$ ). Fourteen patients from Group $A$ and 7 patients from Group B dropped out either due to personal reasons, delaying in follow up or not willing to continue the treatment. Therefore, 35 patients (34 female+1 male) in Group A and 36 patients (34 female+2 male) in Group B completed the study. The mean age of Group A and Group B patients was $33.5 \pm 8.1$ and $35.4 \pm 7.5$ years respectively ( $p>0.05)$; and the mean body weight was $61.5 \pm 9.6 \mathrm{~kg}$ and $62.5 \pm 8.2 \mathrm{~kg}$ respectively $(p>0.05)$. Detail baseline fatigue score and serum TSH and FLT4 levels of patients of Group A and B are shown in Table-1. The mean values of different fatigue scores and the serum $\mathrm{TSH}$ and $\mathrm{FT}_{4}$ levels of patients of two groups were identical and not significantly different (Table-1).

Table-1: Baseline fatigue scores, serum $\mathrm{TSH}_{\mathrm{H}}$ and $\mathrm{FT}_{4}$ levels of study population

\begin{tabular}{lccc}
\hline \multirow{2}{*}{ Variables } & \multicolumn{3}{c}{ Baseline values (mean \pm SD) } \\
\cline { 2 - 4 } & Group A & Group B & p value* \\
\hline FSS score & $40.9 \pm 3.9$ & $42.9 \pm 6.3$ & 0.11 \\
$\mathrm{PF}$ score & $9.6 \pm 1.9$ & $10.4 \pm 2.4$ & 0.13 \\
$\mathrm{MF}$ score & $5.2 \pm 1.5$ & $5.8 \pm 2.2$ & 0.21 \\
$\mathrm{TSH} \mu \mathrm{IU} / \mathrm{mL}$ & $2.4 \pm 1.6$ & $2.5 \pm 1.4$ & 0.79 \\
$\mathrm{FT}_{4} \mathrm{ng} / \mathrm{dl}$ & $1.3 \pm 0.2$ & $1.3 \pm 0.2$ & 0.92 \\
\hline Note: FSS: & Fatigue severity & scale, PF: & Physical \\
fatigue, MF: Mental fatigue; *student's t-test.
\end{tabular}

Table-2 shows the detail changes in fatigue scores in patients of group $A$ and $B$ after 8 weeks of treatment and follow up. In Group-A patients, the mean MF score improved significantly $(5.2 \pm 1.5$ vs 4.6 $\pm 1.4 ; p=0.01$ ) from baseline score after 8 weeks while the FSS and PF scores did not improve

Table-2: Status of fatigue score and serum TSH and FT levels of Group-A and B cases after 8 weeks of treatment compared to corresponding baseline values

\begin{tabular}{|c|c|c|c|c|c|c|c|c|}
\hline \multirow{2}{*}{ Variables } & \multicolumn{4}{|c|}{$\begin{array}{c}\text { Group } A(n=35) \\
\text { (mean } \pm S D)\end{array}$} & \multicolumn{4}{|c|}{$\begin{array}{c}\text { Group B }(n=36) \\
\text { (mean } \pm S D)\end{array}$} \\
\hline & $\begin{array}{c}\text { At } \\
\text { baseline }\end{array}$ & $\begin{array}{l}\text { After } 8 \\
\text { weeks }\end{array}$ & $\begin{array}{c}\% \\
\text { change }\end{array}$ & $\begin{array}{c}\mathbf{p} \\
\text { value }\end{array}$ & $\begin{array}{c}\text { At } \\
\text { baseline }\end{array}$ & $\begin{array}{l}\text { After } 8 \\
\text { weeks }\end{array}$ & $\begin{array}{c}\% \\
\text { change }\end{array}$ & $\begin{array}{c}p \\
\text { value }\end{array}$ \\
\hline FSS score & $40.9 \pm 3.9$ & $39.4 \pm 6.2$ & 3.8 & 0.09 & $42.9 \pm 6.3$ & $28.7 \pm 4.9$ & 33.2 & $<0.01$ \\
\hline PF score & $9.6 \pm 1.9$ & $9.1 \pm 2.5$ & 4.8 & 0.18 & $10.4 \pm 2.4$ & $5.4 \pm 1.8$ & 47.7 & $<0.01$ \\
\hline MF score & $5.2 \pm 1.5$ & $4.6 \pm 1.4$ & 20 & 0.01 & $5.8 \pm 2.2$ & $3.4 \pm 1.2$ & 40.2 & $<0.01$ \\
\hline $\mathrm{TSH} \mu \mathrm{IU} / \mathrm{ml}$ & $2.4 \pm 1.6$ & $2.3 \pm 1.6$ & 2.9 & 0.84 & $2.5 \pm 1.4$ & $3.0 \pm 1.5$ & 19.0 & 0.13 \\
\hline $\mathrm{FT}_{4} \mathrm{ng} / \mathrm{dl}$ & $1.3 \pm 0.2$ & $1.4 \pm 0.3$ & 7.8 & 0.11 & $1.3 \pm 0.2$ & $1.3 \pm 0.2$ & 1.6 & 0.59 \\
\hline
\end{tabular}

Note: FSS: Fatigue severity scale, PF: Physical fatigue, MF: Mental fatigue; *student's t-test. 
significantly $(p>0.05)$. In Group-B patients, the mean FSS, PF and MF scores improved significantly $(p<0.01)$ from baseline score after 8 weeks of treatment with L-carnitine along with $\mathrm{L}^{-\mathrm{LT}_{4}}$ treatment. The rates of change were $33.2 \%, 47.7 \%$ and $40.2 \%$ for FSS, PF and MF fatigue scores respectively. The serum TSH and $\mathrm{FT}_{4}$ levels remained within normal limit in both Group-A and Group-B patients after 8 weeks.

Table-3: Comparison of fatigue score and serum TSH and $\mathrm{FT}_{4}$ levels of Group A and B patients after 8 weeks of treatment

\begin{tabular}{lllc}
\hline \multirow{2}{*}{ Variables } & \multicolumn{3}{c}{ After 8 weeks (mean \pm SD) } \\
\cline { 2 - 4 } & Group A & Group B & p Value \\
\hline FSS score & $39.4 \pm 6.2$ & $28.7 \pm 4.9$ & $<0.01$ \\
$\mathrm{PF}$ score & $9.1 \pm 2.5$ & $5.4 \pm 1.8$ & $<0.01$ \\
$\mathrm{MF} \mathrm{score}$ & $4.6 \pm 1.4$ & $3.4 \pm 1.2$ & $<0.01$ \\
$\mathrm{TSH} \mu \mathrm{IU} / \mathrm{mL}$ & $2.4 \pm 1.6$ & $3.0 \pm 1.5$ & 0.08 \\
$\mathrm{FT}_{4} \mathrm{ng} / \mathrm{dl}$ & $1.4 \pm 0.3$ & $1.3 \pm 0.2$ & 0.16 \\
\hline
\end{tabular}

Table-4: Number of patients improved in Group-A and Group-B after 8 weeks of intervention

\begin{tabular}{|c|c|c|c|c|c|}
\hline \multirow{3}{*}{$\begin{array}{c}\text { Fatigue } \\
\text { score }\end{array}$} & \multirow{2}{*}{\multicolumn{2}{|c|}{$\begin{array}{c}\begin{array}{c}\text { Group-A } \\
\mathrm{n}=35\end{array} \\
\text { Patient } \\
\text { improved }\end{array}$}} & \multirow{2}{*}{\multicolumn{2}{|c|}{$\begin{array}{c}\begin{array}{c}\text { Group-B } \\
\mathrm{n}=36\end{array} \\
\text { Patient } \\
\text { improved }\end{array}$}} & \multirow{3}{*}{$\begin{array}{c}p \\
\text { value* }\end{array}$} \\
\hline & & & & & \\
\hline & $\begin{array}{c}\text { Number } \\
(\%)\end{array}$ & $\begin{array}{c}95 \% \\
\mathrm{Cl}\end{array}$ & $\begin{array}{c}\text { Number } \\
(\%)\end{array}$ & $\begin{array}{c}95 \% \\
\mathrm{Cl}\end{array}$ & \\
\hline FSS & $\begin{array}{c}7 \\
(20.0)\end{array}$ & $\begin{array}{l}0.1 \\
0.36\end{array}$ & $\begin{array}{c}32 \\
(88.9)\end{array}$ & $\begin{array}{l}0.75 \\
0.96\end{array}$ & $<0.01$ \\
\hline PF & $\begin{array}{c}5 \\
(14.3)\end{array}$ & $\begin{array}{l}0.1 \\
0.29\end{array}$ & $\begin{array}{c}28 \\
(77.8)\end{array}$ & $\begin{array}{l}0.62 \\
0.88\end{array}$ & $<0.01$ \\
\hline $\mathrm{MF}$ & $\begin{array}{c}2 \\
(5.7)\end{array}$ & $\begin{array}{l}0.02 \\
0.19\end{array}$ & $\begin{array}{c}17 \\
(47.2)\end{array}$ & $\begin{array}{l}0.32 \\
0.63\end{array}$ & $<0.01$ \\
\hline All & $\begin{array}{c}1 \\
(2.9)\end{array}$ & $\begin{array}{l}0.01 \\
0.15\end{array}$ & $\begin{array}{c}17 \\
(47.2)\end{array}$ & $\begin{array}{l}0.32 \\
0.63\end{array}$ & $<0.01$ \\
\hline
\end{tabular}

Table-3 shows that FSS, PF and MF scores of Group$B$ patients reduced significantly $(p<0.01)$ compared to Group-A patients after 8 weeks of treatment. The reduction of fatigue scores indicated improvement. Out of 35 patients in Group-A, the FSS, PF and MF scores improved in 20\%, 14.3\% and $5.7 \%$, cases respectively while these rates were $88.9 \%, 77.8 \%$ and $47.2 \%$ in Group-B patients (Table-4). In Group-A, only $2.9 \%$ patient experienced improvement in all three fatigue component compared to $47.2 \%$ in Group-B cases.

The incidence of adverse events was mild. Lcarnitine was generally well tolerated and produced no severe adverse events. In the group treated with L-carnitine (Group-B: 36 patients), 3 patients complained of nausea, 1 patient complained of diarrhea and 2 patients complained of epigastric discomfort but none stopped or discontinued the drug. No serious adverse effects were seen in this group that needed dose adjustment or withdrawal of drug.

\section{Discussion}

$\mathrm{L}-\mathrm{T}_{4}$ administered dose was adequate to produce euthyroid condition in all our patients of both groups and L- carnitine had no effect on serum TSH and free $T_{4}$ levels.

The present study investigated the effect of Lcarnitine supplementation on fatigue-related symptoms in hypothyroid patients. It was observed that FSS and PF scores of Group-A patients did not decrease significantly after 8 weeks than that of baseline scores whereas the mental fatigue score decreased significantly $(p<0.01)$. The MF score appeared to improve considerably probably due to $\mathrm{L}-\mathrm{T}_{4}$ administration. However, earlier study reported that hypothyroid patients receiving $L-T_{4}$ therapy continued to complain of impaired mood or impaired cognitive performance despite normal serum TSH levels [9]. It may be relevant to mention that, cognitive performance or cognitive function includes a series of mental performances like memory, attention, orientation, visual-spatial organization, etc. According to other studies, $\mathrm{L}-\mathrm{T}_{4}$ treatment is usually effective in treating cognitive decrements $[28,29]$. Perhaps in the present study, $\mathrm{L}-\mathrm{T}_{4}$ administration could successfully recover the levels of mental fatigue and in this regard our observation is similar to those studies. 
In the present study, all the fatigue scores of Group-B patients significantly $(P<0.01)$ decreased compared to baseline values of the same group as well as Group-A after 8 weeks of L-carnitine treatment. The reason why patients of hypothyroidism experience persistent symptoms of fatigue despite apparently adequate $T_{4}$ replacement is not absolutely clear. The process of ATP production might get interrupted because of absence or inadequate amounts of thyroid hormones. Therefore, the ATP production probably might not be completely recovered following $\mathrm{L}-\mathrm{T}_{4}$ administration alone in Group-A patients. Conversely, considerable alleviation of fatigue (in Group-B cases) could be due to enhancement of fatty acid oxidation and increase of ATP generation by administration of L-carnitine [20].

Also, L-carnitine shuttle perhaps mediates translocation of acetyl moiety from mitochondria into cytosol in brain tissue and thus contributes to the synthesis of acetylcholine and acetylcarnitine [30]. Acetylcarnitine improves brain energy, cellular macromolecules (neurohormones) and synaptic transmission of multiple neurotransmitters [31]. These might have aided to reduce mental fatigue by L-carnitine in Group B patients. In our study, significant numbers of Group-B patients experienced reduction of fatigue scores compared to Group-A cases. Oral administration of L-carnitine has been reported to bring about a reduction of total body fat mass and improve physical capacity and cognitive activity [32].

In addition, fatigue could be due to impaired ATP formation. Administration of thyroid hormone and L-carnitine helps in transport and oxidation of long chain fatty acids resulting in ATP formation [33-37]. Alleviating effect by L-carnitine administration in hypothyroid patients (receiving $L-T_{4}$ ) for a period of 12 weeks has been reported in another study [23]. Fatigue alleviation has been reported in patients suffering from multiple sclerosis by administering Lcarnitine orally [38].

Fatigue is a non-specific and subjective symptom which may be affected by various physiological and physical factors as well as by social, personal and environmental factors. Currently, fatigue is a popular field of research in medical science. Till now the molecular mechanisms underlying fatigue are not well understood. Although, detail mechanisms of fatigue improving effect of $L$ carnitine in hypothyroid patients are not available at present, it may be hypothesized that besides increasing long chain fatty acid oxidation and accelerating energy production, oxidative stress reduction may be a part of the mechanism by the Lcarnitine. Hypothyroidism is associated with increased oxidative stress [39] and raised plasma malondialdehyde (MDA) and glutathione (GSH) levels. These markers of oxidative stress remain at higher levels in hypothyroid patients receiving replacement therapy [40]. Oxidative stress levels remain at higher levels in patients with chronic fatigue syndrome [41]. L-carnitine administration has been observed to be associated with significant reduction in oxidative stress and increases in antioxidant enzymes activities in coronary artery disease patients [42].

The present study had several limitations. Wide age range of the study population was a limitation of present study. The sample size was small and the serum L-carnitine level was not estimated at baseline and after 8 weeks of intervention. Again different confounding factors like menopausal oestrogen level of women aged over 40 years were overlooked and serum MDA levels were not estimated.

The results obtained from the present study indicate that concurrent administration of Lcarnitine along with thyroid hormone replacement could significantly alleviate the fatigue status of patients suffering from hypothyroidism.

\section{References}

1. Allam M. Detection of prevalence and characterization of thyroid disorder patients in Dhaka: a survey based study. Thesis. Dhaka: BRAC University; 2012.

2. Murgod R, Soans G. Changes in electrolytes and lipid profile in hypothyroidism. Int J Life Sci Pharma Res. 2012; 2(3): 185-194.

3. Canaris GJ, Manowitz NR, Mayor G, Ridgway EC. The colorado thyroid disease prevalence study. Arch Intern Med. 2000; 160: 526-534.

4. Paul AK, Miah SR, Mamun AA, Islam S. Thyroid Disorder in Khulna District: A community based 
study. Bangladesh Med Res Counc Bull. 2006; 32: 66-71.

5. Akhter N, Hasan S. Subclinical hypothyroidism and hyperprolectinemia in infertile women: Bangladesh perspective after universal salt iodination. Internet J Endocrinology. 2008; 5: 357-563.

6. Sayeed MA, Mohsena M, Haq T, Morshed AHG, Afroz S, Tomalika N, et al. Prevalence of hypothyroidism in different occupational groups of Bangladeshi population. IMC J Med Sci. 2019; 13(2): 002.

7. Rafa MR. Awareness and prevalence of hyperthyroidism and hypothyroidism in endocrine disordered patients of Bangladesh. Thesis. Dhaka: East West University; 2016.

8. Saravanan P, Chau WF, Roberts N, Vedhara K, Gruwood R, Dayan CM. Psychological wellbeing in patients on 'adequate' doses of L$\mathrm{T}_{4}$ : result of a large, controlled communitybased questionnaire study. Clin Endocrinol (Oxf). 2002; 57: 577-585.

9. Wekking EM, Appelhof BC, Fliers E, Schene AH, Huyser J, Tijssen JGP, et al. Cognitive functioning and wellbeing in euthyroid patients on thyroxine replacement therapy for primary hypothyroidism. Eur J Endocrinol. 2005; 153(6): 747-753.

10. Holmes GP, Kaplan JE, Gantz NM, Komaroff AZ, Schonberger LB, Straus SE, et al. Chronic fatigue syndrome: a working case definition. Ann Intern Med. 1988; 108(3): 387-389.

11. Malaguarnera M, Vacante M, Bertino G, Neri S, Malaguarnera M, Gargante MP, et al. The supplementation of acetyl-L-carnitine decreases fatigue and increases quality of life in patients with hepatitis $C$ treated with pegylated interferon- $\alpha 2 b$ plus ribavirin. $J$ Interferon Cytokine Res. 2011; 31(9): 653-659.

12. Galland S, Georges B, Borgne FL, Conductier G, Dias JV, Demarquoy J. Thyroid hormone control carnitine status through modifications of gamma-butyrobetaine hydroxylase activity and gene expression. Cell Mol Life Sci. 2002; 59(3): 540-545.

13. Jackson-Hayes $L$, Song $S$, Lavrentyev EN, Jansen MS, Hillgartner FB, Tian $L$, et al. A thyroid hormone response unit formed between the promoter and first intron of the carnitine palmitoyltransferase-I alpha gene mediates the liver specific induction by thyroid hormone. J Biol Chem. 2003; 278(10): 7964-7972.

14. Sinclair C, Gilchrist JM, Hennessey JV, Kandala M. Muscle carnitine in hypo and hyperthyroidism. Muscle Nerve. 2005; 32(3): 357-359.

15. Cave MC, Hurt RT, Frazire TH, Matheson PJ, Garrison RN, Mcclain CJ, et al. Obesity inflammation and the potential application of pharmaco nutrition. Nutr Clin Pract. 2008; 23(1): 16-34.

16. Bremer J, Hokland B. Role of carnitinedependent metabolic pathways in heart disease without primary ischemia. $Z$ Kardiol. 1987; 76: 9-13.

17. Borum PR. Carnitine and lipid metabolism. Bol Asoc Med P R. 1991; 83(3): 134-135.

18. Flanagan JL, Simmons PA, Vehige J, Willcox MDP, Garrett $Q$. Role of carnitine in disease. Nutr Metab (Lond). 2010; 7: 30.

19. Pucci E, Chiovato L, Pinchera A. Thyroid and lipid metabolism. Int J Obes Relat Metab Disord. 2000; 24: 109-112.

20. Liu YY, Brent GA. Thyroid hormone crosstalk with nuclear receptor signalling in metabolic regulation. Trends Endocrinol Metab. 2010; 21(3): 166-173.

21. Winter SC, Aczels S, Curry C, Hutchinson H, Hogue R, Shung A. Plasma carnitine deficiency: clinical observations in 51 patients. Am J Dis Child. 1987; 141(6): 660-665.

22. Cruciani RA, Dvorkin E, Homel P, Malamud S, Culliney B, Lapin J, et al. Safety, tolerability and symptom outcomes associated with L-carnitine supplimentation in patients with cancer, fatigue and carnitine deficiency: a phase I/II study. J Pain Symptom Manage. 2006; 32(6): 551-559.

23. An JH, Kim YJ, Kim KJ, Kim SH, Kim NH, Kim, HY, et al. L-carnitine supplementation for the management of fatigue in patients with hypothyroidism on levothyroxine treatment: a randomized, double- blind, placebo-controlled trial. Endocr J. 2016; 63(10): 885-895. 
24. Krupp LB, Larocca NG, Muir-Nash J, Steinberg $A D$. The Fatigue severity scale: application to the patients with multiple sclerosis and systemic lupus erythromatosus. Arch Neurol. 1989; 46(10): 1121-1123.

25. Valko PO, Bassetti CL, Bloch KE, Held U, Baumann CR. Validation of the Fatigue severity scale in a swiss cohort. Sleep. 2008; 31(11): 1601-1607.

26. Hjollund NH, Andersen JH, Bech P. Assessment of fatigue in chronic disease: a bibliographic study of fatigue management scales. Health Qual Life Outcomes. 2007; 5: 12.

27. Wessely S, Powell R. Fatigue Syndroms: a comparison of chronic "postviral" fatigue with neuromuscular and affective disorders. J Neurol Neurosurg Psychiatry. 1989; 52(8): 940-948.

28. Capet C, Jego A, Denis P, Noel D, Clerc I, Cornier $\mathrm{AC}$, et al. Is cognitive change related to hypothyroidism reversible with replacement therapy? Rev Med Interne. 2000; 21(8): 672-678.

29. Miller KJ, Parsons TD, Whybrow PC, Rasgon KVHN, Maetinez AHD, Silverman DH, et al. Memory improvement with treatment of hypothyroidism. Int J Neurosci. 2006; 116(8): 895-906.

30. Nalecz KA, Nalecz MJ. Carnitine: a known compound, a novel function in neural cells. Acta Neurobiol Exp (Wars). 1996; 56(2): 597-609.

31. Virmani A, Binienda Z. Role of carnitine esters in brain neuropathology. Mol Aspects Med. 2004; 25(5-6): 533-549.

32. Malaguarnera M, Cammalleri L, Gargante MP, Vacante M, Colonna V, Motta M. L-carnitine treatment reduces severity physical and mental fatigue and increase cognitive functions in centinarians: a randomized and controlled clinical trial. Am J Clin Nutr. 2007; 86(6): 1738-1744.

33. Santanasto AJ, Glynn NW, Jubrias SA, Conley $\mathrm{KE}$, Boudreau RM, Amati $\mathrm{F}$, et al. Skeletal muscle mitochondrial function and fatigability in older adults. J Gerontol A Biol Sci Med Sci. 2015; 70(11): 1379-1385.

34. Pistone G, Murino A, Leotta C, Dell'arte S, Finocchiaro G, Malaguarnera M. Levocarnitine administration in elderly subjects with rapid muscle fatigue. Drug Aging. 2003; 20(10): 761-767.

35. Gramignano G, Lusso RM, Madeddu C, Massa E, Serpe R, Deiana L, et al. Efficacy of L-carnitine administration on fatigue, nutritional status, oxidative stress, and related quality of life in 12 advanced cancer patients undergoing anticancer therapy. Nutrition. 2006; 22(2): 136-145.

36. Arduini A, Bonomini M, Savica V, Amato A, Zammit V. Carnitine in metabolic disease: potential for pharmacological intervention. Pharmacol Ther. 2008; 120(2): 149-156.

37. Malaguarnera $M$, Vacante $M$, Giordano $M$, Pennici G, Bella R, Rampello $\mathrm{L}$, et al. Oral acetyl-L-carnitine therapy reduces fatigue in overt hepatic encephalopathy: a randomized, double-blind, placebo-controlled study. Am J Clin Nutr. 2011; 93(4): 799-808.

38. Tomassini V, Pozzilli C, Onesti E, Pasqualetti $P$, Marinelli F, Pisani A, et al. Comparison of the effects of acetyl L-carnitine and amantadine for the treatment of fatigue in multiple sclerosis: results of a pilot, randomised, double-blind, crossover trial. J Neurol Sci. 2004; 218(1-2): 103-108.

39. Nanda N, Bobby Z, Hamide A. Inflammation and oxidative stress in hypothyroids: additive effects on cardiovascular risk. Indian J Physiol Pharmacol. 2011; 55(4): 351-356.

40. Baskol G, Atmaca H, Tanrivardi F, Baskol M, Kocer D, Bayram F. Oxidative stress and enzymatic antioxidant status in patients with hypothyroidism before and after treatment. Exp Clin Endocrinol Diabetes. 2007; 115(8): 522-526.

41. Kennedy G, Spence VA, Mclaren M, Hill A, Underwood C, Belch JJ. Oxidative stress levels are raised in chronic fatigue syndrome and are associated with clinical symptoms. Free Radic Biol Med. 2005; 39(5): 584-589.

42. Lee $B$, Lin J, Lin Y, Lin P. Effect of L-carnitine supplementation on oxidative stress and antioxidant enzymes activities in patients with coronary artery diseases: a randomized, placebo-controlled trial. Nutr J. 2014; 13: 79. 